\title{
The Utilization of Surface Free Energy for Predicting Flowability of Filler-lubricant or Filler-glidant Mixtures
}

\author{
P. TONGLAIROUM, T. NGAWHIRUNPAT, T. ROJANARATA, P. AKKARAMONGKOLPORN, N. NATTAPULWAT ${ }^{* *}$ AND \\ P. OPANASOPIT*
}

Pharmaceutical Development of Green Innovations Group (PDGIG), Faculty of Pharmacy, ${ }^{1}$ Department of Pharmaceutical Technology, Faculty of Pharmacy, Silpakorn University, Nakhon Pathom 73000, Thailand

Tonglairoum, et al.: Surface Free Energy for Predicting Flowability of Binary Mixtures

\begin{abstract}
The aim of this study was to apply the knowledge of surface free energy for the flowability prediction of pharmaceutical excipients. In order to predict the flowability, the spreading coefficient was calculated from the surface free energy of each material using Wu's equation. The resulting spreading coefficient could indicate which material would spread over another in a binary mixture. In this study, the binary mixture consisted of filler (lactose, or dibasic calcium phosphate) and a lubricant (magnesium stearate), talc or silicon dioxide. The flowability of each binary mixture was assessed using angle of repose and compressibility index data. Finally, the resulting spreading behaviour was compared with flowability parameters. The calculated spreading coefficient values revealed that magnesium stearate, talc and silicon dioxide would spread over the surface of lactose and dibasic calcium phosphate. The evaluated flowability from the two methods found that all of the lubricants could improve the flowability of the binary mixtures. Moreover, these results were in accordance with predictions. In conclusion, the spreading coefficient could be a suitable tool for predicting the flowability of powder mixtures.
\end{abstract}

Key words: Surface free energy, tablets, flowability, filler-lubricant mixtures, filler-glidant mixtures

In the design of pharmaceutical formulations, an understanding of the surface free energy of pharmaceutical solids is essential ${ }^{[1-3]}$. This knowledge can support the selection of the excipient used in the formulation when interfacial interactions and compatibility of the formulation components have been established ${ }^{[4]}$. Previous studies have reported applications of surface free energy and spreading coefficient in the selection of suitable excipients for drug formulation ${ }^{[5]}$, the formation of pellets from 1 to 2 component powder compositions ${ }^{[5]}$ and an investigation of the mucoadhesion of polycarbophil and pig intestinal mucosa ${ }^{[6]}$.

Surface free energy $(\gamma)$ is an essential physicochemical property of a solid. The technique for calculating the surface free energy from wettability measurements is extensively used ${ }^{[7-9]}$. Wu and Brzozowski ${ }^{[10]}$ described the surface free energy obtained as the sum of the dispersive and the polar (p) components. The surface free energies of solid materials can be determined using a technique of contact angle measurements, using two liquids with known polarities. They can be calculated according to Eqn. 1.

$$
(1+\cos \theta)=\frac{4\left(\gamma_{s}^{\mathrm{d}} \gamma_{1}^{\mathrm{d}}\right)}{\gamma_{\mathrm{s}}^{\mathrm{d}}+\gamma_{1}^{\mathrm{d}}}+\frac{4\left(\gamma_{\mathrm{s}}^{\mathrm{P}} \gamma_{1}^{\mathrm{P}}\right)}{\gamma_{\mathrm{s}}^{\mathrm{P}}+\gamma_{1}^{\mathrm{P}}}
$$

Where, $\gamma_{\mathrm{s}}{ }^{\mathrm{d}}$ is the surface free energy of the dispersive component of the solids, $\gamma_{1}{ }^{\mathrm{d}}$ is the surface tension of the dispersive component of the liquids, $\gamma_{\mathrm{s}}^{\mathrm{p}}$ is the surface free energy of the polar component of the solids, $\gamma_{1}{ }^{\mathrm{p}}$ is the surface tension of the polar component of the liquids and $\theta$ is the contact angle. After obtaining the surface free energies values, the spreading coefficient can be calculated and the interaction between the two substances may be predicted. Spreading coefficient is defined as the difference between the adhesion work and the cohesion work. The spreading coefficient (S12) of a substance (1) over the surface of another substance (2) can be established according to Eqn. $2^{[3,11]}$.

This is an open access article distributed under the terms of the Creative Commons Attribution-NonCommercial-ShareAlike 3.0 License, which allows others to remix, tweak, and build upon the work non-commercially, as long as the author is credited and the new creations are licensed under the identical terms

Accepted 16 December 2016

Revised 25 October 2016

Received 14 June 2016

*Address for correspondence

E-mail: opanasopit_p@su.ac.th; nattapulwat_n@su.ac.th 
$\mathrm{S} 12=4\left[\frac{\gamma_{1}^{\mathrm{d}} \tilde{\mathrm{a}}_{2}^{\mathrm{d}}}{\gamma_{1}^{\mathrm{d}}+\gamma_{2}^{\mathrm{d}}}+\frac{\gamma_{1}^{\mathrm{P}} \gamma_{2}^{\mathrm{P}}}{\gamma_{1}^{\mathrm{P}}+\gamma_{2}^{\mathrm{P}}}-\frac{\gamma_{1}}{2}\right]$

Where, $\mathrm{S}$ is the spreading coefficient of the liquid over the substrate, $\gamma$ is the surface free energy, $\gamma^{\mathrm{p}}$ is the polar component and $\gamma^{\mathrm{d}}$ is the dispersive component.

Ahfat et al. ${ }^{[12]}$ reported the successful use of surface energy data to predict the adhesion of a binary system onto a third component. The results revealed that there is good correlation between theoretical data and visual observations; spreading coefficients for solid-solid interactions provide good predictions of macroscopic events such as powder mixing. To the best of our knowledge, the use of surface energy data to predict the flowability of drug formulations has not been previously reported. In the present study, the information from the surface free energy and the spreading coefficient was used for the prediction of the flowability of filler-lubricant mixtures. Spreading coefficients (S12 and S21) were calculated from the surface free energy of each material using Wu's equation. The resulting spreading coefficient could indicate which material would spread over the other in the binary mixture and the results were compared with the flowability values obtained from angle of repose and compressibility index from the experiment.

\section{MATERIALS AND METHODS}

The model substances used as received were magnesium stearate (MGST; Glaxo welcome, UK), Talc (HCP, China), colloidal silicon dioxide $\left(\mathrm{SiO}_{2}\right.$; Evonik industries, Germany), dibasic calcium phosphate (DCP; Budenheim, Germany) and lactose (Carter Holt Harvey, New Zealand), talc or talcum (Talc power-magnesium oxide mining, China). The rest of the chemicals used were of analytical grade.

\section{Contact angle measurement on flat surface of the powders:}

Contact angle measurement was performed using the Wilhelmy plate method which was partially modified from the system used by Afhat et al. ${ }^{[12]}$ Briefly, the powders were stuck to a glass cover slip $(26 \times 22 \mathrm{~mm})$ using double-sided adhesive tape. Non-adhering powder was removed by brushing. The contact angles of two different liquids (water and formamide) on the surface of the powders were determined using a drop shape analyser after placing a small drop of each liquid $(10 \mu 1)$ on the surface of each powder using a micropipette. All contact angle measurements were carried out at room temperature. The average of 5 measurements was used for further calculations. The surface free energy and spreading coefficient were calculated according to Eqns. 1 and 2, respectively, using FTA32 software.

\section{Preparation of filler-lubricant or filler-glidant mixtures:}

Powder mixing was performed using a cube mixer (Model PA1540, Yeo Heng factory). The fillers and lubricants or glidants were mixed in various ratios. The compositions of the prepared mixtures are shown in Table 1. The amount of mixture was $120 \mathrm{~g}$ and the mixing process was performed for $10 \mathrm{~min}$.

\section{Angle of repose:}

The angle of repose measurements of each filler powder, lubricant powder, glidant powder and the binary mixtures were carried out using a fixed funnel method. Briefly, the material was poured through a funnel to form a cone. The tip of the funnel was held close to the growing cone and slowly raised as the pile grew. The height and width of the cone were measured. The angle

\section{TABLE 1: FILLER TO LUBRICANT RATIOS}

\begin{tabular}{cc}
\hline Substance & Filler to lubricant ratio \\
\hline Lactose:MGST & $99.75: 0.25$ \\
& $98.17: 1.83$ \\
& $96.59: 3.41$ \\
& $95.00: 5.00$ \\
Lactose:Talc & $99.00: 1.00$ \\
& $96.00: 4.00$ \\
& $93.00: 7.00$ \\
Lactose:SiO & $90.00: 10.00$ \\
& $99.90: 0.10$ \\
& $99.60: 0.40$ \\
DCP:MGST & $99.30: 0.70$ \\
& $99.00: 1.00$ \\
& $99.75: 0.25$ \\
DCP:Talc & $98.17: 1.83$ \\
& $96.59: 3.41$ \\
& $95.00: 5.00$ \\
& $99.00: 1.00$ \\
DCP:SiO & $96.00: 4.00$ \\
& $93.00: 7.00$ \\
& $90.00: 10.00$ \\
& $99.90: 0.10$ \\
& $99.60: 0.40$ \\
& $99.30: 0.70$ \\
& $99.00: 1.00$ \\
\hline
\end{tabular}


of repose was calculated as the inverse tangent of the ratio between the height and half the width of the base of the cone.

\section{Carr's compressibility index:}

The flowability of each filler powder, lubricant powder, glidant powder and the binary mixtures were investigated using Carr's compressibility index. The Carr's compressibility index was calculated from the bulk and tapped densities. The bulk density of each powder was measured by placing the powder $(100 \mathrm{mg}$ for talc, DCP and lactose, $14.89 \mathrm{~g}$ for $\mathrm{SiO}_{2}$ and $70 \mathrm{~g}$ for MGST) into a $250 \mathrm{ml}$ cylinder without compaction. The apparent volume of the powder was recorded, and then the bulk density $(\mathrm{g} / \mathrm{ml})$ was calculated by dividing the mass by the apparent volume. The tapped densities were determined using the same procedure as the bulk densities, but the apparent volume was recorded after tapping the samples using a tapping machine. The Carr's compressibility index was calculated according Eqn. 3, compressibility index $=($ tapped density-bulk density)/tapped density) $\times 100$.

\section{RESULTS AND DISCUSSION}

Applying knowledge of the surface free energy to the selection of excipient used in drug formulation could be very useful. This could save time and cost of the development of drug formulations. It has been reported that the mixing properties of binary and ternary blends can be predicted using surface energy calculations ${ }^{[12,13]}$. In the experiment, the surface free energies were calculated according to Wu's method using the information obtained from the contact angle of the two reference liquids on the surface of the excipient powders. The surface free energy data were then used to determine the spreading coefficient which was expected to act as a tool to predict the flowability of filler-lubricant or filler-glidant mixtures.

The specific surface energy of a solid may possibly be estimated from contact angle measurements using liquids which exhibit different and known polar and dispersive components ${ }^{[14,15]}$. Therefore, the contact angles of two liquids (water and formamide) on the surface of each excipient were determined using a drop shape analyser and the surface free energies were computed according to Wu's method. The measured contact angle and calculated surface free energy of each excipient were listed in Table 2 . The surface free energies of the excipients were used to calculate the spreading coefficients (S12 and S21), and the results were presented in Table 3 . The spreading coefficient (S12) can be used to account for the ability of an excipient to spread over another in a binary mixture. Many research studies have shown evidence of the strong relationship between the spreading coefficient of a material and its ability to cover the surface of another material ${ }^{[5,16-19]}$. When the spreading coefficient is positive, the spreadability of an excipient over the other can be predicted. In fact, positive spreading coefficient values of lubricants or glidants over model fillers enable their adherence to the filler surface and may lead to an increase in the flowability of the mixture powder ${ }^{[3,19]}$. In contrast, when the spreading coefficient is negative, the excipient cannot spread over another material ${ }^{[3]}$. From Table 3, the spreading coefficients of lactose over MGST and MGST over lactose were -100.79 and 10.79 , respectively. In this case, lactose could not spread over MGST; however,

TABLE 2: CONTACT ANGLE AND SURFACE FREE ENERGY

\begin{tabular}{lccccc}
\hline Substances & Contact angle of water & Contact angle of formamide & $\gamma$ & $\gamma^{\mathbf{d}}$ & \multicolumn{1}{c}{$\gamma^{\mathrm{p}}$} \\
\hline Lactose & $35.25 \pm 1.49$ & $17.39 \pm 3.69$ & 62.68 & 26.94 & 35.74 \\
$\mathrm{DCP}$ & $50.40 \pm 2.51$ & $34.26 \pm 2.05$ & 53.03 & 24.15 & 28.38 \\
$\mathrm{MGST}$ & $130.88 \pm 1.86$ & $127.20 \pm 2.66$ & 6.89 & 1.80 & 5.09 \\
$\mathrm{Talc}$ & $96.44 \pm 1.78$ & $25.49 \pm 1.21$ & 29.87 & 23.06 & 6.81 \\
$\mathrm{SiO}_{2}$ & $60.99 \pm 0.54$ & $36.74 \pm 3.95$ & 48.53 & 27.58 & 20.95 \\
\hline
\end{tabular}

TABLE 3: SPREADING COEFFICIENT OF BINARY MIXTURES

\begin{tabular}{lccc}
\hline Substance 1 & Substance 2 & \multicolumn{2}{c}{ Experimental values as measured } \\
\cline { 3 - 4 } & & $\mathrm{S}(\mathbf{1}, \mathbf{2})$ & $\mathrm{S}(\mathbf{2}, \mathbf{1})$ \\
\hline Lactose & $\mathrm{MGST}$ & -100.79 & 10.79 \\
DCP & $\mathrm{MGST}$ & -82.10 & 10.18 \\
Lactose & $\mathrm{TalC}$ & -52.78 & 12.84 \\
DCP & $\mathrm{TalC}$ & -36.91 & 9.41 \\
Lactose & $\mathrm{SiO}_{2}$ & -18.02 & 10.28 \\
DCP & $\mathrm{SiO}_{2}$ & -6.35 & 2.65 \\
\hline
\end{tabular}


MGST, which acted as a lubricant, could spread over lactose. Therefore, an increase in flowability could be predicted from the lactose-MGST mixture as per the spreading coefficient results. A similar pattern of results was observed in DCP-MGST, lactose-talc, DCP-talc, lactose- $\mathrm{SiO}_{2}$, and $\mathrm{DCP}-\mathrm{SiO}_{2}$ mixtures. These findings revealed that a rise in flowability may also be expected from these mixtures.

To determine the correlation between the theoretical (calculated) data and the experimental data, an assessment of flowability values through angles of repose and compressibility indices of the fillerlubricant mixtures was performed. The angle of repose and compressibility index of each of the fillers and lubricants were also measured and the results were displayed in Table 4. It can be seen from the results that the information obtained from both the angle of repose and the compressibility index provided similar results. Lactose and DCP exhibited quite poor flowability while talc, $\mathrm{SiO}_{2}$ and MGST presented better flowability.

The amount of flowing agent used was also expected to have an effect on the flowability of the filler-lubricant mixtures. In the experiment, various amounts of MGST $(0.25,1.83,3.41$ and $5.00 \%)$, talc $(1.00,4.00,7.00$ and $10.00 \%)$ or $\mathrm{SiO}_{2}(0.10,0.40,0.70$ and $1.00 \%)$ were mixed with the fillers (lactose or DCP). After mixing lactose or DCP with MGST, the mixture exhibited better flowability as suggested by the angle of repose and compressibility index data (Table 5). Usually, the flowability of the filler-lubricant mixtures increased after raising the amounts of MGST. Table 6 showed the angle of repose and compressibility index data of lactose-talc and DCP-talc mixtures. When lactose or DCP were mixed with talc, small increases in flowability of the mixtures were observed. It can be seen from the results that after increasing the amount of talc, little improvement in the flowability of the filler-lubricant mixtures was observed. This may be because the range of the flowing agents used, which were in normal ranges for tableting, may not have been high enough to distinguish the difference in flowability. The flowability

TABLE 4: MEAN ANGLE OF REPOSE AND CARR'S COMPRESSIBILITY INDEX OF THE DILUENTS

\begin{tabular}{lcc}
\hline Substance & Angle of repose & $\begin{array}{c}\text { Carr's compressibility } \\
\text { index }\end{array}$ \\
\hline Lactose & 55.45 & 47.14 \\
$\mathrm{DCP}$ & 52.95 & 48.95 \\
$\mathrm{Talc}$ & 47.68 & 50.56 \\
$\mathrm{SiO}_{2}$ & 49.17 & 22.92 \\
$\mathrm{MGST}$ & 37.85 & 34.91 \\
\hline
\end{tabular}

TABLE 5: MEAN ANGLE OF REPOSE AND CARR'S COMPRESSIBILITY INDEX OF LACTOSE OR DCP AFTER BEING MIXED WITH DIFFERENT PERCENTAGES OF MGST

\begin{tabular}{lcccc}
\hline MGST (\%) & \multicolumn{2}{c}{$\begin{array}{c}\text { Angle of repose } \\
(\mathbf{n}=10)\end{array}$} & \multicolumn{2}{c}{$\begin{array}{c}\text { Compressibility } \\
\text { index }(\mathbf{n}=2)\end{array}$} \\
\cline { 2 - 5 } & Lactose & DCP & Lactose & DCP \\
\hline 0.25 & 55.21 & 55.15 & 48.70 & 47.03 \\
1.83 & 47.36 & 51.61 & 40.59 & 46.79 \\
3.41 & 46.01 & 49.80 & 42.24 & 48.03 \\
5.00 & 45.00 & 47.55 & 41.18 & 48.29 \\
\hline
\end{tabular}

TABLE 6: MEAN ANGLE OF REPOSE AND CARR'S COMPRESSIBILITY INDEX OF LACTOSE OR DCP AFTER BEING MIXED WITH DIFFERENT PERCENTAGES OF TALC

\begin{tabular}{lcccc}
\hline Talc (\%) & \multicolumn{2}{c}{$\begin{array}{c}\text { Angle of repose } \\
(\mathrm{n}=10)\end{array}$} & \multicolumn{2}{c}{$\begin{array}{c}\text { Compressibility index } \\
(\mathrm{n}=2)\end{array}$} \\
\cline { 2 - 5 } & Lactose & DCP & Lactose & DCP \\
\hline 1.00 & 56.5 & 55.51 & 44.28 & 47.67 \\
4.00 & 55.63 & 55.02 & 43.88 & 46.60 \\
7.00 & 53.49 & 55.03 & 43.93 & 47.37 \\
10.00 & 51.66 & 53.65 & 43.98 & 47.37 \\
\hline
\end{tabular}

data of lactose- $\mathrm{SiO}_{2}$ and $\mathrm{DCP}-\mathrm{SiO}_{2}$ were presented in Table 7. The angle of repose results revealed an increase in flowability of the mixtures when compared to those of the unmixed fillers. An increase in the $\mathrm{SiO}_{2}$ amount resulted in an improvement in flowability of the mixtures. In addition, the compressibility index data were in accordance with the angle of repose results except in the case of the $\mathrm{DCP}-\mathrm{SiO}_{2}$ mixture. The improvement in flowability of the filler-lubricant mixtures or filler-glidant mixtures may be because the lubricants or glidants filled the surface cavities of the fillers. This selective adhesion to the surface improved the flowability of the powder by smoothing the surface of the filler particles-the particles became more spherical with a smoother surface and lessened the frictional forces, thus improving flow ${ }^{[20-22]}$. For lubricants added to a formulation, the most favourable quantity is usually a balance between the lubrication needs for tablet flow or ejection and the negative impacts on the tablet properties. Moreover, it should be noted that the glidant and lubricant used in the formulation are hydrophobic in nature. Higher concentrations may delay the disintegration and dissolution profile. Further research should be carried out to assess the dissolution and disintegration properties of the tablets.

The investigation to assess the correlation between the predictions of flowability calculated from the surface free energy and the flowability data from the 
TABLE 7: MEAN ANGLE OF REPOSE AND CARR'S COMPRESSIBILITY INDEX OF LACTOSE OR DCP AFTER BEING MIXED WITH DIFFERENT PERCENTAGES OF $\mathrm{SIO}_{2}$

\begin{tabular}{lcccc}
\hline $\mathrm{SiO}_{2}(\%)$ & \multicolumn{2}{c}{$\begin{array}{c}\text { Angle of repose } \\
(\mathrm{n}=10)\end{array}$} & \multicolumn{2}{c}{$\begin{array}{c}\text { Compressibility } \\
\text { index }(\mathrm{n}=2)\end{array}$} \\
\cline { 2 - 5 } & Lactose & DCP & Lactose & DCP \\
\hline 0.10 & 45.54 & 50.41 & 48.66 & 46.99 \\
0.40 & 41.30 & 49.49 & 46.26 & 48.04 \\
0.70 & 41.93 & 48.82 & 45.85 & 47.93 \\
1.00 & 40.76 & 48.10 & 39.56 & 47.21 \\
\hline
\end{tabular}

experiment revealed that the theoretical data calculated from the surface free energy correlated well with the experimental flowability data. Thus, the surface free energy and spreading coefficient may be used to predict the flowability of filler-lubricant mixtures. These results reveal the importance of knowledge of the surface free energy which can be used as a tool for selecting the excipients for drug formulation. However, other factors should also be taken into account.

In this study, we examined the application of surface free energy and spreading coefficient for the prediction of the flowability of filler-lubricant mixtures. The use of surface energy and spreading coefficient data taken from contact angle measurement of the excipients has proved to be a useful tool for predicting the flowability of binary mixtures. A good correlation between theoretical data and the data obtained from the flowability tests was obtained, however other factors such as the properties of excipients should be considered. In addition, the amount and type of flowing agents used were observed to have an effect on the flowability of the mixtures.

\section{Acknowledgements:}

The authors would like to thank the Faculty of Pharmacy, Silpakorn University for financial support and Miss Juthaporn Peantaweeponrung, Miss Suchada Lueamsichan and Miss Suchamon Waradee for their research assistance.

\section{Conflict of interest:}

There are no conflicts of interest mentioned.

\section{Financial support and sponsorship:}

Nil.

\section{REFERENCES}

1. Fowkes FM. Dispersion force contributions to surface and interfacial tensions, contact angles and heats of immersion. Adv Chem 1964;43:99-111.

2. Buckton G, Darcy P. The influence of additives on the recrystallization of amorphous spray dried lactose. Int J Pharm 1995;121:81-7.

3. Baki G, Bajdik J, Djuric D, Knop K, Kleinebudde P, PintyeHódi K. Role of surface free energy and spreading coefficient in the formulation of active agent-layered pellets. Eur J Pharm Biopharm 2010;74:324-31.

4. Tüske Z, Regdon Jr G, Erős I, Srčič S, Pintye-Hódi K. The role of the surface free energy in the selection of a suitable excipient in the course of a wet-granulation method. Powder Technol 2005;155:139-44.

5. Planinšek O, Pišek R, Trojak A, Srčič S. The utilization of surface free-energy parameters for the selection of a suitable binder in fluidized bed granulation. Int J Pharm 2000;207:77-88.

6. Lehr CM, Bouwstra JA, Bodde HE, Junginger HE. A surface energy analysis of mucoadhesion: contact angle measurements on polycarbophil and pig intestinal mucosa in physiologically relevant fluids. Pharm Res 1992;9:70-5.

7. Buckton G. Characterization of small changes in the physical properties of powders of significance for dry powder inhaler formulations. Adv Drug Deliv Rev 1997;26:17-27.

8. Planinšek $\mathrm{O}$, Trojak A, Srčič $\mathrm{S}$. The dispersive component of the surface free energy of powders assessed using inverse gas chromatography and contact angle measurements. Int J Pharm 2001;221:211-7.

9. Bajdik J, Fehér M, Pintye-Hódi K. Effect of plasticizer on surface of free films prepared from aqueous solutions of salts of cationic polymers with different plasticizers. Appl Surf Sci 2007;253:7303-8.

10. $\mathrm{Wu} \mathrm{S}$, Brzozowski KJ. Surface free energy and polarity of organic pigments. J Colloid Interface Sci 1971;37:686-90.

11. Rowe RC. Binder-substrate interactions in granulation: a theoretical approach based on surface free energy and polarity. Int J Pharm 1989;52:149-54.

12. Ahfat NM, Buckton G, Burrows R, Ticehurst MD. Predicting mixing performance using surface energy measurements. Int $\mathrm{J}$ Pharm 1997;156:89-95.

13. Steele DF, Moreton RC, Staniforth JN, Young PM, Tobyn MJ, Edge S. Surface energy of microcrystalline cellulose determined by capillary intrusion and inverse gas chromatography. AAPS J 2008;10:494-502.

14. Gindl M, Sinn G, Gindl W, Reiterer A, Tschegg S. A comparison of different methods to calculate the surface free energy of wood using contact angle measurements. Colloids Surf A Physicochem Eng Asp 2001;181:279-87.

15. Sharma PK, Hanumantha RK. Analysis of different approaches for evaluation of surface energy of microbial cells by contact angle goniometry. Adv Colloid Interface Sci 2002;98:341-463.

16. Baki G, Bajdik J, Djuric D, Knop K, Kleinebudde P, PintyeHodi K. Role of surface free energy and spreading coefficient in the formulation of active agent-layered pellets. Eur J Pharm Biopharm 2010;74:324-31.

17. Andersson TM, Mohamed A, Eastoe J. A highly hydrophobic anionic surfactant at oil-water, water-polymer and oilpolymer interfaces: Implications for spreading coefficients, polymer interactions and microencapsulation via internal phase separation. Colloids Surf A Physicochem Eng Asp 2013;436:1048-59. 
18. Andrade R, Skurtys O, Osorio F, Zuluaga R, Gañán P, Castro C. Wettability of gelatin coating formulations containing cellulose nanofibers on banana and eggplant epicarps. LWTFood Sci Technol 2014;58:158-65.

19. Shmeis RMA, Alshwwabkeh ID, Alkrad JM, Mohammad MA. Surface free energy data to predict the surface modification ability of force control agents. JJPS 2015;8:141-52.

20. Perrault M, Bertrand F, Chaouki J. An investigation of magnesium stearate mixing in a V-blender through gammaray detection. Powder Technol 2010;200:234-45.

21. Roblot-Treupel L, Puisieux F. Distribution of magnesium stearate on the surface of lubricated particles. Int J Pharm 1986;31:131-6.

22. Morin G, Briens L. The Effect of lubricants on powder flowability for pharmaceutical application. AAPS PharmSciTech 2013;14:1158-68. 